\title{
An International Project for the Development of Data Handling Skills of Teachers and Pupils
}

\author{
NEVILLE DAVIES† \\ neville.davies@ntu.ac.uk \\ The Royal Statistical Society Centre for Statistical Education, \\ Nottingham Trent University, UK \\ DOREEN CONNOR \\ doreen.connor@ntu.ac.uk \\ The Royal Statistical Society Centre for Statistical Education, \\ Nottingham Trent University, UK \\ NANCY SPENCER \\ nancy.spencer@treasury.qld.gov.au \\ Office for Economic and Statistical Research, Queensland Treasury, Brisbane, Australia
}

\begin{abstract}
In this paper we provide an overview of the international CensusAtSchool project, designed, written and implemented first in the UK from October 2000 - April 2001 for pupils aged $7-16$ in primary and secondary schools. It has been adapted for similar aged school children in South Africa and Australia and was implemented in those countries in July and October 2001, respectively. We present our motivation, aims and objectives for carrying out such a project and show some results of analysis from the returns we have received from all three countries. Key outputs from the project include: worksheets that are suitable for enhancing data handling skills of pupils; a training course that wraps information and communications technology with data handling skills that is suitable to enhance the professional development of teachers; a raised awareness amongst pupils and teachers of the need to properly collect, present and analyze primary data; a contribution to improving the statistical numeracy and thinking skills of both teachers and pupils.
\end{abstract}

Keywords: CensusAtSchool, teaching data handling, training, worksheets

\section{The UK CensusAtSchool Project}

During 1999 a funding partnership was formed between the Royal Statistical Society (RSS) Centre for Statistical Education at Nottingham Trent University in the UK, the Department for Education and Employmentfunded UK Maths Year 2000 initiative and the UK Office for National Statistics (ONS). The ONS was responsible for conducting the April 2001

$\dagger$ Requests for reprints should be sent to Neville Davies, The Royal Statistical Society Centre for Statistical Education, Nottingham Trent University, UK. 


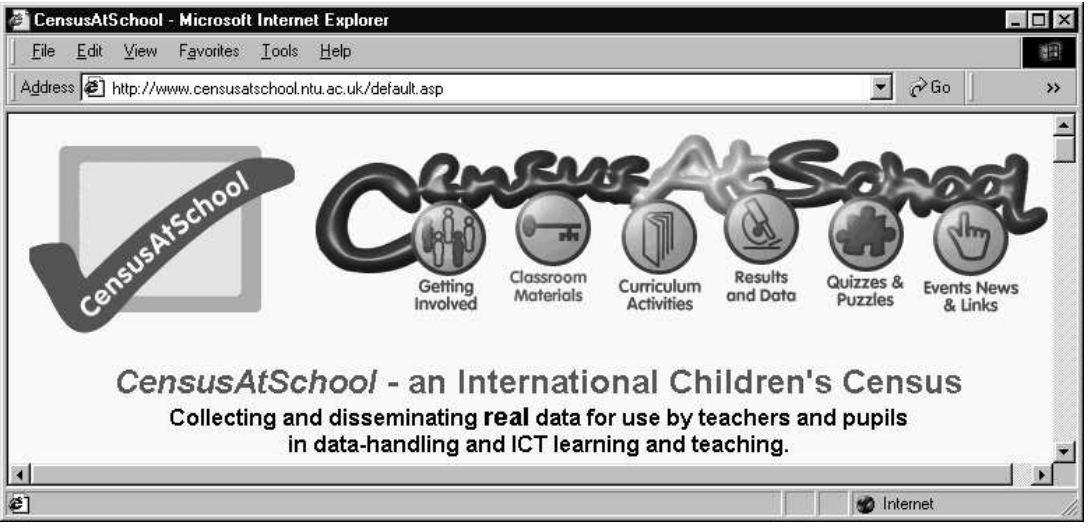

Figure 1. The UK CensusAtSchool homepage

UK National census and saw the CensusAtSchool project as a precursor to it, potentially raising its profile and encouraging a more positive image through association with a school-based event that is children-friendly and up to date.

The aims of the project were (i) to involve young people, ages $7-16$, in schools in collecting data about themselves, a real life activity that has interest; (ii) to improve young people's data handling ability within all relevant school subjects; (iii) to encourage effective Information and Communication Technology (ICT) learning and teaching, including the use of the Internet for educational purposes; (iv) to provide data and contextual material for teachers and pupils to use in their schoolwork across the national curriculum; (v) to raise awareness of the UK Census in April 2001; (vi) to demonstrate the purpose and processes involved in national censuses and get pupils to appreciate the problems involved in collecting census data; (vii) to make comparisons between the responses in different countries.

An early description of the project is given by Connor et al. [1]. Some other developments are described in Connor and Davies [2]. The CensusAtSchool website homepage is illustrated in Figure 1.

\section{The UK Web portal}

With the emphasis being on using a simple census with school children, the RSS Centre for Statistical Education devised 18 questions, divided into 
three sections, occupying three columns on a single A4 questionnaire sheet. The first column contains questions about the children themselves, the second their household and the third their school. Some of the questions were made deliberately identical to ones on the UK adult census, while others were designed to appeal to the child's own interest and enthusiasms. Two versions of the questionnaire form were developed, one targeted for pupils aged 7 to 11, and the other for pupils aged 11 to 16 . These forms can be viewed at, and are downloadable from, the UK section available from the portal web site http://www.censusatschool.ntu.ac.uk.

The children were asked to fill in the forms as part of a whole-class activity and, as part of that, we suggested that a couple of children from the class should take on the role of census enumerators and transfer the data onto the electronically-supplied summary spreadsheet. The completed spreadsheet was then emailed back to us as an attachment. Note that in order to do this it was only necessary to have one computer with access to the Internet in each school. The idea was that by giving children a greater understanding of the processes involved in conducting a census in their own classroom, they would take home questions and comments about their class activity and create an interest in their parents for the adult census.

We now have a large database, suitably anonymized, that has been created and made available for educational purposes. From our web site, schools, and indeed anyone else with access to the Internet, can take random samples from the database for use for learning and teaching in classrooms. See http://www.censusatschool.ntu.ac.uk/results.asp.

Also, we have a large, and expanding portfolio of worksheets that focus on the use of ICT and data handling skills across the UK school curriculum. These can be viewed and downloaded after browsing our web site at www.censusatschool.ntu.ac.uk/curriculum.asp. All these worksheets sheets are in both Adobe .pdf and Word .doc format, the former format being visually appealing, while the latter can be altered to suit local needs.

There is no copyright on these worksheets, but the RSS Center for Statistical Education would like to be informed of any innovative alterations to them so that it can make them available for general educational use through dissemination from its web site.

\section{The Internationalization of the CensusAtSchool Project}

The success of the project in the UK, with its balanced and focussed aims, has shown us very clearly that it has a far wider appeal. It can be run equally well using paper methods, computer technology or a combination of the two. The questions we ask on the questionnaires can be asked of school 
children across the globe, with just a few adjustments needed to reflect local culture and traditions. The potential for exchange of information between school-aged children could be (is) a unique way to assess global, social and other changes and has the added bonus of providing ICT, education and motivation reasons for the teachers and children that get involved.

We have produced a worldwide database which educators and learners can use to both contribute to, and use, in order to enhance their teaching and learning. The current contributors to the database are Statistics South Africa (www.censusatschool.org.za/index.htm), and Queensland Australia (www.oesr.qld.gov.au/censusatschool/home.htm). Northern Territory, South Australia and New Zealand are all now either implementing, or planning to implement, the CensusAtSchool project. The Office of Economic and Statistical Research (OESR) at the Queensland Treasury Department along with the School of Mathematics at Queensland University of Technology sponsored the project in Queensland schools during June - August 2001. They promoted the activities through posters and flyers, taking part in National Science Week there, having a presence on local TV stations and writing articles for the local Brisbane newspaper. They also ran a State-wide poster competition for schools that decided to take part.

Statistics South Africa embraced the project most enthusiastically from June - December 2001, and continue to do so. They spent R5.5 million promoting a pilot and subsequently the full version in 22,000 of the 26,000 schools in South Africa in October 2001. A promotional video was produced with prizes for schools that took part and, most importantly, the Director General for Education in South Africa backed the project. Statistics New Zealand, in conjunction with the University of Auckland, will be running a pilot census shortly with the intention of carrying out a full CensusAtSchool project later in the year.

\section{Country Findings}

In this section we present some of the key findings from each of the countries that have taken part.

In the UK. Manchester United was the UK's favorite soccer team, even in the South of England; cats just topped dogs as the most common pet; overall $40 \%$ of the children had their own mobile phones, rising to $60 \%$ in the 11-16 age range; over $80 \%$ had access to a computer at home; the most common distance to school was less than $1 \mathrm{~km}$ taking 10 minutes to get there; most common methods of travel were walking in England, bus in Wales and car in Northern Ireland. 
The results were launched in February 2001 and the UK media coverage was extensive, attracting comment from every national daily newspaper, national and local radio and television, media web sites and regional newspapers. In fact the local Nottingham newspaper, who expressed disgust that even in a city with two national soccer teams the children in the survey chose Manchester United as their most popular soccer team, even wrote an editorial on the matter!

In Queensland, Australia. Over 330 schools from all education districts across Queensland registered electronically on the web site hosted by the OESR at the Queensland Treasury Department. Responses were received from 176 schools, representing $52.2 \%$ of those registered. There were a total of 14,665 individual responses - 8,128 primary and 6,537 secondary pupils. The first ranked sporting team was the Brisbane Broncos, followed by Manchester United, and this was true for both boys and girls.

In South Africa. The results in this section are for the pilot CensusAtSchool project. A sample of 277 schools was drawn from a list of relevant schools registered with the Department of Education. Two sampling frames were created, one for primary schools (grades 3 to 7 ) and one for secondary schools (grades 8 to 12 ). The sample was stratified by province, and then by education district. Within each education district, the schools were ordered by highest grade and lowest grade. Special schools were added to the sample. Some of the findings were that $94 \%$ of scholars have a radio in their home, but only $46 \%$ have a tap inside the dwelling; $9 \%$ of children take an hour or more to reach school each day; $25 \%$ of boys and $29 \%$ of girls in Grades 8 to 12 chose English as their favorite subject, while $15 \%$ of boys and $12 \%$ of girls chose mathematics; $48 \%$ of boys chose soccer as their favorite sport, as against $10 \%$ of girls, but $40 \%$ of girls chose netball as their favorite sport, as against $1 \%$ of boys; $36 \%$ of learners in KwaZulu-Natal selected soccer as their favorite sport, as against $17 \%$ in the Western Cape.

The data that have been collected allow some interesting comparisons to be made between countries, and can enhance statistical understanding as well. For example, the relationship between height and right foot length of pupils can be examined between countries using overlay scatter plotting, and a simple linear model may be explored for each country's data.

The multiple scatter plot (Figure 2) displays samples of size 500 from the country's databases for the two variables height and foot length. Also superimposed on the graph are the corresponding lines of best fit for each country's data.

There is a clear difference between the three sets of data and three linear models estimated for these two variables for each country. For example, 


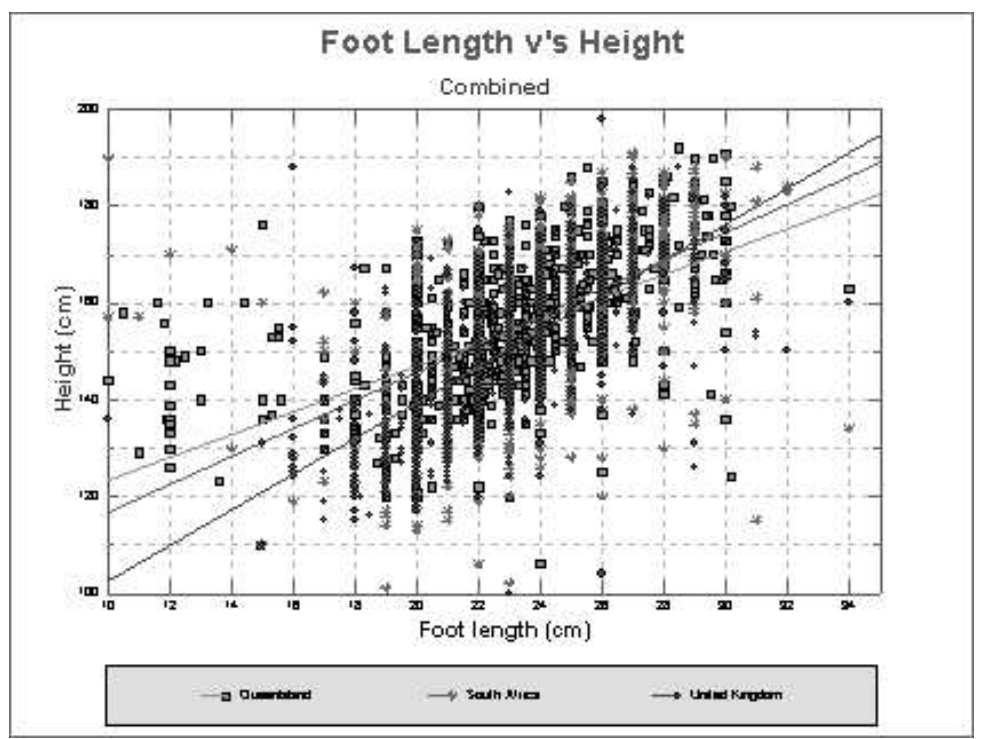

Figure 2. Multiple scatterplot of height versus foot length

there are a number of Queensland responses that, for increasing foot length between 10 and $13 \mathrm{~cm}$, on average no increase in height appears to occur. This feature does not appear for the other two countries. However, an important issue, that can be used to illustrate the need to examine the data more closely, is that foot sizes of $10-13 \mathrm{~cm}$ are unusually small. Questions arise as to whether the data have been mis-recorded, or that there are other, possibly ethnic, issues that may explain the small foot sizes.

\section{Curriculum task sheets}

The web site contains over 50 curriculum task sheets, in both .pdf and .doc formats, which enable pupils aged $7-16$ to carry out activities in data handling across a broad range of curriculum subjects. They are designed to be flexible, for example many can be adapted for a teacher's particular group of pupils, and most of them can be used in paper or ICT formats.

The worksheets are based on simple ideas and the tasks that the pupils carry out are aimed at areas not covered by many textbooks. For example, the Dirty Data worksheet is deigned to get pupils to appreciate that real 
data can be messy and in order to proceed with just simple and routine data handling sometimes means the data have to be scrutinized for unusual or mistaken data records. Some of the worksheets are flexible enough to allow the teacher's own data to be imported to the worksheet, and often only minimal alterations have to be made to the text of the worksheet.

Using the worksheets the wide variety of tasks that can be carried out across a broad area of learning means that the worksheets often cross normal subject barriers - data handling is a good tool to connect different subjects. The generation of international data offers a rich source of new opportunities for between-country data handling exercises. For more details see Connor and Holmes [4].

\section{Adding Value to Data}

We have developed two further ways for teachers and pupils to use the data that have been collected from the project. Currently we have a database of 120,000 responses, suitably anonymised, from which samples can be taken using web browser technology. First, the web site has a facility for random samples to be taken from each of the three countries' data and from a combined data set of all responses using our random data selector. Second, our dynamic worksheet creator allows unique real data worksheets to be created directly from the database. The expanding portfolio of these will cover a broad range of statistical topics and will be suitable for school and university level work. Students may select worksheets for individual practice with real data problems, and the solutions can be generated as well. Teachers can, subject to password protection, generate batches of unique worksheets, with solutions and data that can be distributed in paper or electronic form to students. All worksheets, solutions and data are returned to the teacher as an email attachment in a zipped file. After unzipping, the worksheets and solutions are stored as Word documents and the data file is stored as a .csv file.

The teacher can choose to use the unique worksheets in any way that is optimal for the topic being delivered. For example, each worksheet could be emailed to individual students for use at a PC or workstation within or outside the school or university. Alternatively they could be printed and distributed in hard copy form. In both cases the teacher will have received the data and suggested solution for each of the exercise worksheets. The .csv files of the uniquely generated data can themselves be read into standard commercial statistical software, so that further exercises and analyzes can be generated for learning and teaching by using them to perform more statistical analyzes. Further details may be found in Connor et al. [3]. 


\section{Adding Value for Teachers}

We have designed and piloted a teacher-training course that wraps ICT training around data handling specifications across a broad range of curriculum subjects. It uses the database of responses from the project and takes a unique approach to provide training and support for teachers in the use of the resources offered by computer-based technology. Also it provides training in the development and use of web-based teaching materials and enables teachers to use and interact with the Internet for within- and cross-curricular data handling activities.

The approach is unique, but its main learning feature is that the task of learning to use the technology is integrated with the task of developing and/or using the technology within the data handling topic area across many curriculum subjects. The course teaches the use of basic computerbased tools, such as word processing, emailing, using spreadsheets and the web, and uses them to develop existing or new web-based teaching and learning resources. Teachers benefit from hands-on experience with each of these tools, and they use their own specialist curriculum knowledge to develop web-based teaching resources specific to their disciplines.

The course is based upon a two-stage approach to learning for the participating teachers. Stage 1 comprises a face-to-face interactive training course lasting two days, while stage 2 will be spread over a month and will involve self-learning and home activities. After receiving the training in stage 1, during the month immediately following the training, the participants will be expected to create computer-based material and activities that are subject-specific and can be used in classes with their students.

After the first stage the learning outcomes are (i) an ability to use confidently information technology methods for learning and teaching; (ii) an ability to locate and retrieve appropriate web resources and material; (iii) an ability to develop ICT-based resources; (iv) knowledge of the basic principles of data handling in an ICT context; (v) the principles of, and reasons for, using samples and censuses.

After the second stage the learning outcomes are (i) ICT-based resources that can be used to enhance and reinforce students' knowledge; (ii) methods that can be used for the further creation of worksheets for use by students; (iii) ICT knowledge and techniques so that teachers can take a lead in the use of technology in the classroom.

The worksheets will be submitted to the RSS Centre for Statistical Education for scrutiny and it is expected they will become part of a resource for all teachers - they will be added, as appropriate, to the international resource available on the CensusAtSchool web site. 


\section{Conclusions}

The CensusAtSchool project provides a unique way to develop statistical numeracy and thinking for both teachers and school children. For school children that take part and use the materials produced it is motivational, can be fun and is, at the same time, educational. It is helpful for the professional development of teachers, both to enhance their statistical knowledge and the associated ICT skills that can be an integral part of taking part in the project. The teacher course wrapping together ICT and data handling uses data collected from the project and also can be used for the professional development of teachers. It has the potential for useful exchange of information between school-aged children and could be a unique way to assess global, social and other changes. It has the added bonus of being a motivational reason for the teachers and children to get involved. Finally it links democratic government activity, such as the need for national surveys and censuses with the use of data to produce information to help people to make evidence based decisions, with data handling in schools. We are in the early stages of a project in which we are developing a way of crafting unique worksheets from real data. Such a facility could be useful to both teachers and students of statistics, especially if it is important that each pupil works with a different set of data. If data are real and interesting then pupils could get extra motivation from working with it. Currently we are running Phase 2 of the project using a questionnaire that is based upon a combination of the original questionnaires used in UK, South Africa and Australia. Participants may fill in the questionnaire using a web form, the data being received directly by the database at the RSS Centre in Nottingham. We intend to run several more phases of the project and extend the number of countries who will take part thus expanding the potential to enhance the data handling and statistical skills of more and more pupils and teachers.

\section{References}

1. D. Connor, N. Davies and P. Holmes. CensusAtSchool 2000. Teaching Statistics, 22:66-70, 2000.

2. D. Connor and N. Davies. An International Resource for Learning and Teaching. Teaching Statistics, 24:59-61, 2002.

3. D. Connor, N. Davies and B. Payne. Web-based Project and Key Skills Work. Teaching Statistics, 24:62-65, 2002.

4. D. Connor and P. Holmes. Classroom and Worksheet Activities across the Curriculum. Teaching Statistics, 24:55-58, 2002. 


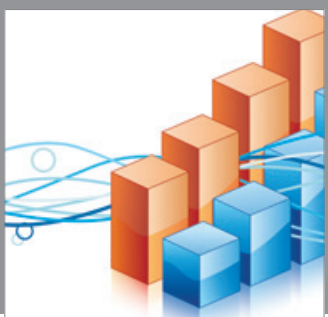

Advances in

Operations Research

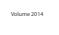

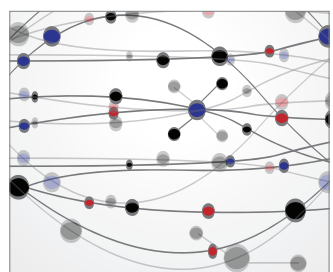

\section{The Scientific} World Journal
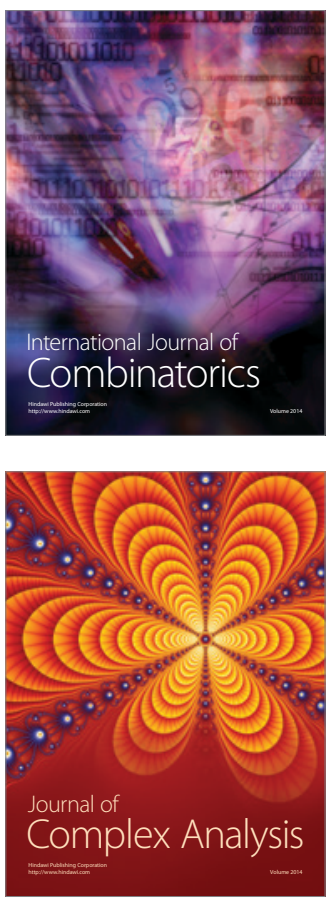

International Journal of

Mathematics and

Mathematical

Sciences
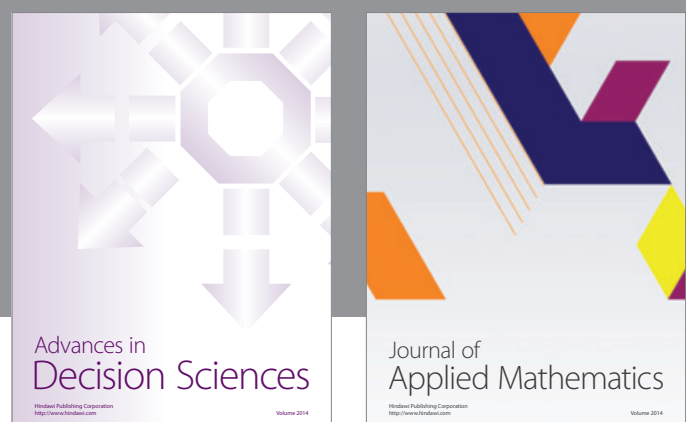

Journal of

Applied Mathematics
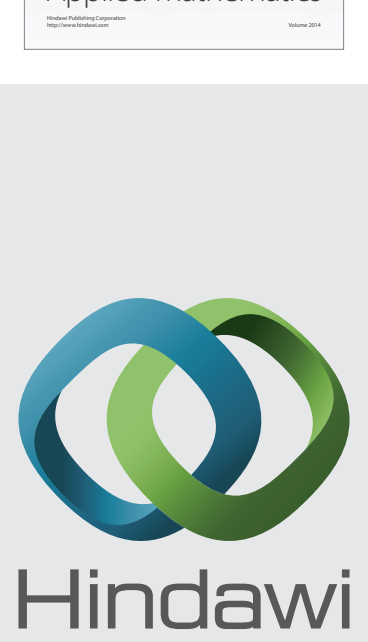

Submit your manuscripts at http://www.hindawi.com
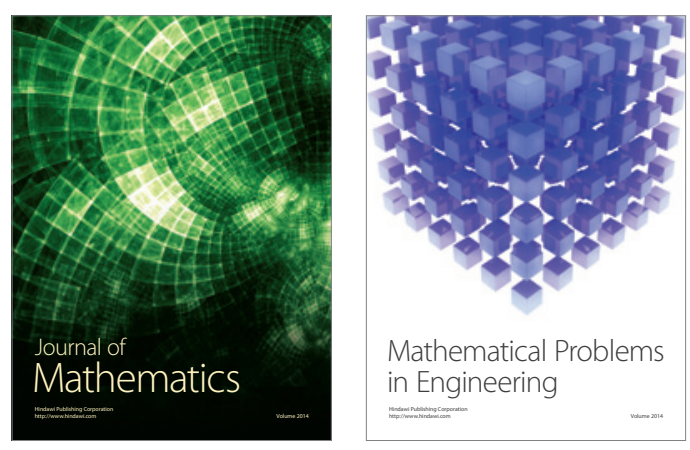

Mathematical Problems in Engineering
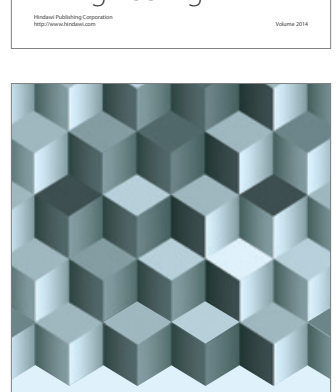

Journal of

Function Spaces
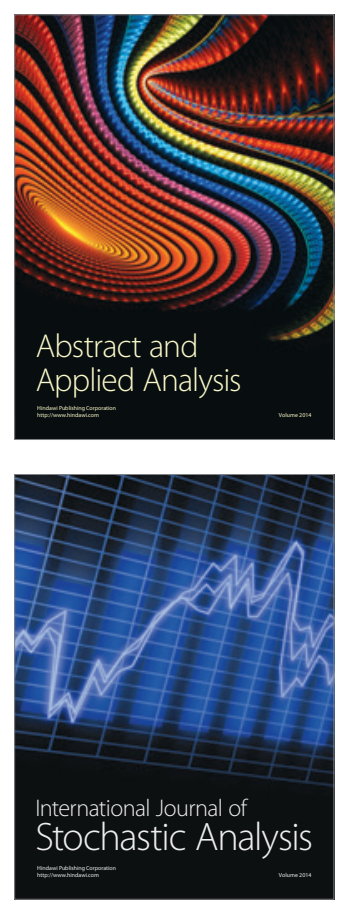

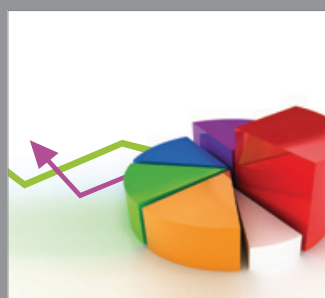

ournal of

Probability and Statistics

Promensencen
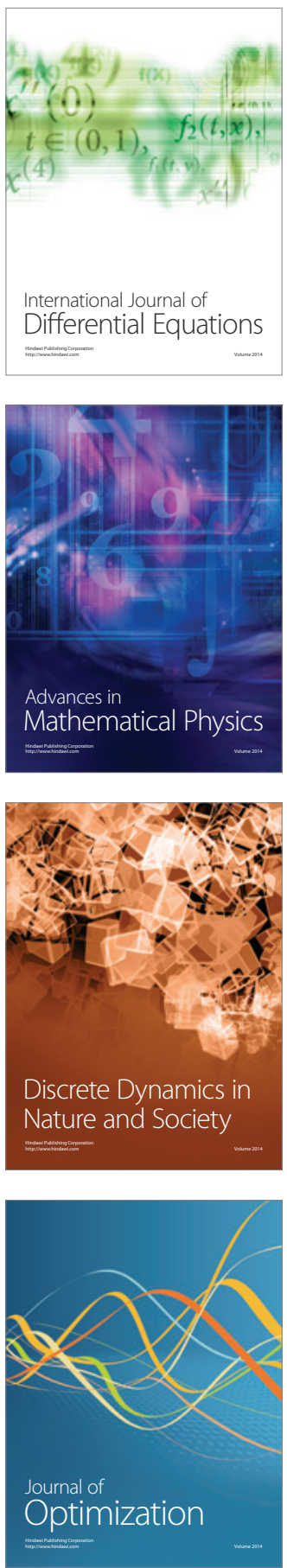